\title{
BMJ A comparison of individual versus Open community influences on youth smoking behaviours: a cross-sectional observational study
}

To cite: Adachi-Mejia AM, Carlos HA, Berke EM, et al. A comparison of individual versus community influences on youth smoking behaviours: a cross-sectional observational study. BMJ Open 2012;2:e000767. doi:10.1136/bmjopen-2011000767

- Prepublication history and additional material for this paper are available online. To view these files please visit the journal online (http://dx. doi.org/10.1136/bmjopen2011-000767).

Received 6 March 2012 Accepted 30 July 2012

This final article is available for use under the terms of the Creative Commons Attribution Non-Commercial 2.0 Licence; see http://bmjopen.bmj.com

For numbered affiliations see end of article

Correspondence to Dr Anna M Adachi-Mejia; anna.adachi-mejia@ dartmouth.edu

\section{ABSTRACT}

Objectives: To compare individual with community risk factors for adolescent smoking.

Design: A cross-sectional observational study with multivariate analysis.

Setting: National telephone survey.

Participants: 3646 US adolescents aged 13-18 years in 2007 recruited through a random digit-dial survey.

Outcome measures: Ever tried smoking and, among experimental smokers, smoking intensity (based on smoking in past 30 days).

Results: One-third of participants $(35.6 \%, \mathrm{~N}=1297)$ had tried smoking. After controlling for individual risk factors, neither tobacco outlet density nor proximity were associated with tried smoking or smoking intensity. Associations with trying smoking included age (adjusted OR (AOR) $=1.23,95 \% \mathrm{Cl} 1.16$ to 1.31 ), lower socioeconomic status $(A O R=0.82,95 \% \mathrm{Cl} 0.74$ to 0.91 ), sibling smoking ( $A O R=2.13,95 \% \mathrm{Cl} 1.75$ to 2.59), friend smoking ( $\mathrm{AOR}=2.60,95 \% \mathrm{Cl} 2.19$ to 3.10 for some and $A 0 R=7.01,95 \% \mathrm{Cl} 5.05$ to 9.74 for most), movie smoking exposure (AOR=2.66, $95 \% \mathrm{Cl}$ 1.95 to 3.63 ), team sports participation (AOR=0.69, $95 \% \mathrm{Cl} 0.54$ to 0.89 ) and sensation seeking (AOR=7.72, 95\% Cl 5.26 to 11.34). Among experimental smokers, age (AOR=1.32, 95\% $\mathrm{Cl} 1.21$ to 1.44), minority status (AOR $=0.48,95 \% \mathrm{Cl} 0.30$ to 0.79 for Black; AOR $=0.46,95 \% \mathrm{Cl} 0.31$ to 0.69 for Hispanic; AOR $=0.53,95 \% \mathrm{Cl} 0.43$ to 0.85 for mixed race/other), friend smoking ( $\mathrm{AOR}=3.37,95 \% \mathrm{Cl} 2.37$ to 4.81 for some; $A O R=20.27,95 \% \mathrm{Cl} 13.22$ to 31.08 for most), team sports participation (AOR $=0.38,95 \% \mathrm{Cl}$ 0.26 to 0.55 ) and sensation seeking (AOR=6.57, 95\% $\mathrm{Cl} 3.71$ to 11.64 ) were associated with smoking intensity.

Conclusions: The study suggests that interventions and policies to prevent and reduce youth smoking should focus on individual risk factors for smoking, including supporting participation in team sports, minimising exposure to movie smoking, addressing the social influence of friend smoking and addressing experience seeking among high sensation-seekers.

\section{ARTICLE SUMMARY}

Article focus

- This study examines the role of access to tobacco outlets compared to individual risk factors on youth smoking. It is the first to consider the role of community-level factors on adolescent smoking nationwide, the first to jointly examine individual risk factors with communitylevel factors, and the first to examine these factors in the context of individual and community measures of race and ethnicity. The intent of this work is to inform interventional research and policies related to tobacco control efforts directed at youth.

Key messages

- This study compared the association between smoking and individual risk factors-for example, team sports participation and exposure to movie smoking - with community risk factors -for example, density and proximity of tobacco outlets. Associations between community risk factors and smoking were comparatively small and failed to reach statistical significance once accounting for individual risk factors. The findings suggest that public health campaigns to prevent and reduce youth smoking should emphasise individual risk factors.

Strengths and limitations of this study

- This study is national in scope, which is a strength. Owing to cross-sectional data it cannot address temporality. Compared to individual risk factors, tobacco outlet density might be less relevant for minors who are legally constrained in their purchase of tobacco. Further study in adult samples may be indicated. We studied tobacco density and proximity at the home, not the school. Future studies should consider the role of tobacco outlet density and proximity around schools in the context of individual risk factors for adolescent smoking. 


\section{INTRODUCTION}

Preventing adolescent smoking is a key public health imperative. Individual risk factors for youth smoking have been studied for decades. They include personality factors such as sensation seeking, ${ }^{1} 2$ and other social influences like parent ${ }^{3-6}$ and friend ${ }^{7} 8$ smoking. They also include exposure to tobacco marketing ${ }^{9}$ and smoking in entertainment media, ${ }^{10}$ which were both considered causal risk factors in a recent (2012) Surgeon General's report on smoking in adolescents and young adults. ${ }^{11}$ Research has shown that extracurricular activities, such as team sports participation, are associated with preventing youth smoking. ${ }^{12-16}$ Knowledge about these risk factors has informed interventions aiming to minimise adolescents' responsiveness to social risk factors ${ }^{17}$ and policies to minimise adolescent's exposure to tobacco marketing and movies. ${ }^{18}$

In addition to individual risk factors, community influences such as frequent exposure to tobacco outlets ${ }^{19}$ and tobacco outlet density, ${ }^{20}{ }^{21}$ have been associated with youth smoking. Compared to the compelling research on individual risk factors, evidence for community influence is mixed. Studies to date have been regional, have not extensively controlled for individual characteristics and have applied varying approaches to density measurement. ${ }^{21-24}$ To our knowledge, studies have not yet tested whether the association between tobacco outlet density and proximity is confounded by race or social influences like sibling and friend smoking. One study that controlled for individual sociodemographics failed to find an association between tobacco outlet density and youth smoking. ${ }^{25}$

Another area to consider in the context of tobacco outlet density and proximity is their association with neighbourhood characteristics, such as poverty, that may also pose a community risk factor for smoking. Many studies show an association between tobacco outlet density and neighbourhoods characterised by high percentages of minorities ${ }^{21} 2326-29$ and low income, ${ }^{21} 23$ 27-29 although this finding has not been consistent across regions. ${ }^{26}$ Thus, the finding that tobacco outlet density is related to youth smoking could also be confounded by community factors. Nevertheless, the literature was robust enough for Cohen $e t a l^{30}$ to propose policies to limit tobacco outlet density to reduce youth smoking, raising the question of whether individual or community-level factors have greater potential to prevent youth smoking.

This study examines the role of access to tobacco outlets on youth smoking in a national sample of US adolescents. By access, we mean approaching, entering, exiting and having exposure to information imparted to potential customers about tobacco products, including visibility of in-store and storefront advertising. Our focus is twofold-to assess the multivariate association with youth smoking after controlling for other individual and community risk factors, and to compare the sizes of these associations. It is the first to consider the role of community-level factors on adolescent smoking in the
US nationwide, and the first to jointly examine individual social and media influence risk factors with community-level factors. The intent of this work is to inform interventional research and policies related to tobacco control efforts directed at youth.

\section{METHODS}

\section{Theoretical framework}

This study is guided by Bronfenbrenner's Ecological Systems Theory, ${ }^{31-33}$ which posits that development, health and well-being are situated within and shaped by the interactions that occur between the individual and the four systems: microsystem (immediate environment), mesosystem (connections between immediate environments, eg, tobacco outlet density and proximity), exosystem (indirect external environmental settings) and macrosystem (larger cultural context).${ }^{31-33}$ For this study, we include individuallevel variables that are well-established risk factors for smoking: gender, race/ethnicity, socioeconomic status and the personality characteristic of sensation seeking. We also include the microsystem variables of friend smoking, sibling smoking, exposure to smoking in movies and team sports participation. Our mesosystem variables include tobacco outlet density and distance to closest tobacco outlet. Our exosystem variables include proportion population Black, proportion population Hispanic, and proportion of families with income below the poverty level.

\section{Sample recruitment}

A detailed description of the recruitment methods for study participants has been published previously. ${ }^{34}$ Briefly, between June and October 2003, 6522 US adolescents aged 10-14 years were recruited through a random digit-dial telephone survey, which captured a representative sample of US adolescents. Five follow-up surveys were conducted at 8-month intervals. This study involves the fifth follow-up survey conducted in the fall of 2007. Interviewers successfully contacted 3055 (47\%) of the original 6522 adolescents for this round. Loss to follow-up was higher among Blacks, older adolescents, those of lower socioeconomic status, baseline smokers and higher sensation seekers. To address the minority attrition, a sample of 598 Black adolescents (in the same age range) were recruited through lists of residential numbers for US census tracts for which AfricanAmericans represented $20 \%$ or more of the population, resulting in an available sample of 3653 for this study. Parental consent and adolescent assent were required for participation. The study was approved by the Committee for the Protection of Human Subjects at Geisel School of Medicine. The 3653 subjects lived in 3456 unique census tracts, of which the majority $(95.5 \%)$ contained only one subject; 144 tracts $(4.2 \%)$ contained two subjects and 11 tracts $(0.3 \%)$ contained three subjects. Most adolescent residential locations were geocoded to their home street address $(\mathrm{N}=3167)$. When home street address was not available, they were 
geocoded to their ZIP code centroid $(\mathrm{N}=479)$, resulting in a final sample size of $\mathrm{N}=3646$ for this study. We used a complete case analysis approach because only 110 subjects $(3 \%)$ were missing data from one or more variables. The dependent and independent variables include dichotomous, polychotomous and continuous variables. Three variables (smoking intensity, socioeconomic status and sensation seeking) are scales derived from two or more items, constructed using the ' $\alpha$, gen (varlist)' command in Stata 12. The sections below describe how we ascertained the information, constructed the variables, handled outliers and rescaled the variables in order to compare the associations in our analytical models.

\section{Outcome variables}

Ever tried smoking: Respondents were asked, 'How many cigarettes have you smoked in your life?' and those who responded 'none' were categorised as never smokers. Those who responded in a category that indicated lifetime smoking were then asked about past 30-day smoking intensity.

Smoking intensity: Smoking intensity was based on a composite measure using two items $(\alpha=0.82)$ : 'During the past 30 days, on how many days did you smoke cigarettes?' (none, 1-10 days, 11-29 days or every day); 'How many cigarettes have you smoked in your life?' (none, a few puffs, 1-19 cigarettes, 20-100 cigarettes or more than 100 cigarettes). This measure had whole number values ranging from 1 to 7 . We have used this measure in previously published work. ${ }^{35}$

\section{Individual risk factors}

Sociodemographics: Individual measures of age, race and ethnicity were included. Socioeconomic status (SES) was assessed using a standardised composite measure based on parent reports of their own education and household income $(\alpha=0.69)$. The variable was centred around zero and a one-point increase corresponded to a 1 SD increase in SES.

Sibling smoking: Sibling smoking was assessed with the question, 'Do any of your older brothers or sisters smoke cigarettes? (Yes, No)'.

Friend smoking: Friend smoking was assessed with the question, 'How many of your friends smoke cigarettes? Your choices are none, some, or most'.

Exposure to movie smoking: Adolescents' exposure to movie smoking was estimated using the Beach method ${ }^{36}$ for top US box-office hits from 2000 to 2006 ( $\mathrm{n}=384$ ). Movies were content-coded for smoking using previously validated methods. ${ }^{36}$ Each adolescent survey was programmed to randomly select 50 movie titles from the larger pool of 384 movies; respondents were asked whether they had ever seen each movie title. To create a measure of exposure to movie smoking, the number of smoking occurrences in films each adolescent had seen from his/her unique list of 50 movies were summed. A proportion was generated by dividing this number by the number of smoking occurrences that the adolescent would have seen had all 50 movies in the unique list been viewed and this proportion was multiplied by the number of smoking occurrences in the entire parent sample of 384 movies.

Team sports participation: Team sports participation was assessed with a single item, 'Now I'd like you to think about all the sports teams you played on during the past 12 months, including all school, community or recreational teams. How many sports teams did you play on in the past 12 months?'; Team sports participation was skewed right, with responses ranging up to 12 , with 4 at the 95th percentile.

Sensation seeking: Sensation-seeking propensity was assessed using a short 5-item measure: 'I would like to explore strange places', 'I like to do frightening things', 'I like new and exciting experiences, even if I have to break the rules', 'I like to listen to loud music' and 'I like to do dangerous things'. Each of these items had the following response categories for each statement: Strongly Agree, Disagree, Agree and Strongly Agree. These items had a Cronbach's $\alpha$ of 0.70 . The sensation seeking scale ranged from 0 to 15 with 12 at the 95 th percentile.

\section{Community influences \\ Tobacco outlets}

To obtain a national dataset for tobacco outlets, we reviewed North American Industry Classification System (NAICS) codes from 2007 and selected establishments that were likely to sell tobacco products. The Office of Management and Budget developed NAICS for use by Federal statistical agencies in classifying all business establishments based on their primary activity. We selected the 306695 establishments coded as tobacco stores, grocery stores, gas stations and convenience stores and obtained geocoded data from the NAICS Association. Although some businesses classified as department stores, liquor stores and pharmacies may sell tobacco as well (eg, Wal-Mart, Costco, CVS), they were not classified as tobacco outlets because they also include many stores that do not sell tobacco (eg, Sears, Dollar Stores, hospital pharmacies) and the NAICS categories do not allow differentiation between subclasses of stores that do or do not sell tobacco.

\section{Tobacco outlet density using adaptive bandwidth kernel density estimation}

A nationwide density surface of the tobacco outlets using adaptive bandwidth kernel density estimation (KDE) ${ }^{37} 38$ and the LandScan Global Population Database ${ }^{39}$ was produced. Adaptive bandwidth KDE accounts for the underlying population density by limiting the bandwidth of each tobacco outlet to the surrounding population of 1000 people. Setting a limit constrains the influence of a single outlet to a small spatial extent where the population density is high (urban areas) while in rural areas the reach of the tobacco outlet is geographically larger. For sparsely populated regions, the bandwidth of each tobacco outlet was limited to a $25 \mathrm{~km}$ radius to prevent the density 
calculation from expanding to a spatially unreliable distance. The resultant density surface covers the continental US with pixels that are $\sim 0.5$ miles on each side and have a density value in units of tobacco outlets per 1000 people. Each adolescent was assigned the density value based on the pixel at their geocoded location.

\section{Distance to closest tobacco outlet}

ArcGIS Network Analyst (ESRI, Redlands, California, USA) was used to compute the distance along the road network from the adolescent's geocoded location to the closest tobacco outlet. Street data were obtained from the 2008 edition of StreetMap North America, ${ }^{40}$ which was created in 2005 and based on the ground conditions in 2003. Other methods of measuring proximity were also considered, including Euclidian distance and driving time. A sensitivity analysis demonstrated no difference between methods in the final model (data not shown).

\section{Census tract measures of race/ethnicity and poverty}

Community characteristics that might be confounders for tobacco outlet density and proximity were included. Using the US Census 2000 data, the proportion population Black, the proportion population Hispanic and the proportion of families with income below the poverty level for each adolescent's census tract were calculated.

\section{Statistical analysis}

Pearson correlation coefficients were used to describe the association among community influences. Multiple logistic regression was used to assess the association between individual and environmental risk factors and ever tried smoking, and multiple ordered logistic regression was used to assess the odds of being higher on the frequency of smoking scale among smokers. Because the majority of the sample resided in unique census tracts, it was not necessary to fit hierarchical models. Instead, the environmental variables were entered as individual-level risk indicators of the adolescent's environment. Some variables (movie smoking exposure, sensation seeking, team sports participation, tobacco outlet density, distance to the closest outlet, proportion population Black, proportion population Hispanic and proportion families with incomes below the poverty level) were skewed right. In order to limit the influence of high outliers, values higher than the 95th percentile were trimmed to the 95th percentile. In addition, to allow a comparison of effect size among the variables, friend smoking, movie smoking exposure, tobacco outlet density, proportion of families with incomes below the poverty level, sensation seeking and team sports participation were rescaled so that the lowest value was 0 and the highest value was 1 . This scaling procedure allowed a comparison between the dose-response between individual/community measures and adolescent smoking. The 95\% CIs were assessed based on two-tailed hypothesis assumptions.

\section{RESULTS}

Individual and community characteristics

Table 1 describes the characteristics of the adolescents and their correlation with the two smoking outcomes. Only $36 \%$ had tried smoking, and this percentage increased across age categories from $18 \%$ to $56 \%$ in 13-year-olds and 18-year-olds, respectively. Among smokers, mean smoking intensity also increased with age. There were no large differences in tried smoking prevalence across gender or race, but smoking intensity was much lower among Black and Hispanic smokers compared with Whites and those of mixed race. The correlation between community variables and smoking was an order of magnitude lower than correlations with individual characteristics. Whereas tobacco outlet density was positively correlated with trying smoking, it was negatively correlated with smoking intensity. The largest correlation for community predictors was -0.19 , between proportion population Black and smoking intensity, also consistent with lower smoking intensity among minorities at the individual level.

The community characteristics were also correlated with each other. Higher tobacco outlet density was associated with larger proportions of families with incomes below the poverty level, proportion of the population that was Black and Hispanic (table 2). Tobacco outlet density decreased as the distance to nearest outlet increased (correlation=-0.32), but the relationship was not linear. There was a wide range for distance to closest outlet among adolescents living in low tobacco outlet density areas, and a wide range of densities among adolescents living close to an outlet, justifying the consideration of both factors as being independently associated with smoking behaviour.

\section{Relation with ever tried smoking}

Overall, 35.6 percent of respondents reported ever having tried a cigarette. Being male, being Hispanic, having sibling(s) who smoke, being of lower socioeconomic status, having friends who smoke, being older, having more exposure to movie smoking, not playing team sports, being higher in sensation seeking and living in a neighbourhood with higher tobacco outlet density were all significantly associated with ever trying smoking in the unadjusted models (table 3). Two types of multivariate models were built to test these associations with ever trying smoking. In the first, only community-level factors were included; it showed a significant inverse association with proportion of the population that was Black and a significant association with census tract poverty. In the second multivariate model, individual characteristics were added, which substantially improved model fit. Whereas most individual characteristics (sibling smoking, socioeconomic status, friend smoking, age, movie smoking exposure, team sports participation and sensation seeking) were significantly associated with ever trying smoking in the second model, none of the community characteristics were significantly associated with 
Table 1 Individual and community risk factors and smoking outcomes $(\mathrm{N}=3646)$

\begin{tabular}{|c|c|c|c|c|}
\hline Variable & $\mathbf{n}$ & $\begin{array}{l}\text { Proportion } \\
\text { of sample }\end{array}$ & $\begin{array}{l}\text { Proportion } \\
\text { who have tried } \\
\text { smoking }\end{array}$ & $\begin{array}{l}\text { Smoking } \\
\text { intensity } \\
\text { scale mean }\end{array}$ \\
\hline \multicolumn{5}{|l|}{ Categorical } \\
\hline \multicolumn{5}{|l|}{ Age } \\
\hline 13 & 114 & 0.03 & 0.18 & 1.81 \\
\hline 16 & 804 & 0.22 & 0.37 & 2.21 \\
\hline 17 & 769 & 0.21 & 0.43 & 2.57 \\
\hline 18 & 410 & 0.11 & 0.56 & 3.10 \\
\hline \multicolumn{5}{|l|}{ Gender } \\
\hline Male & 1810 & 0.50 & 0.38 & 2.39 \\
\hline Hispanic & 481 & 0.13 & 0.41 & 1.89 \\
\hline Mixed race/other & 256 & 0.07 & 0.38 & 2.37 \\
\hline \multicolumn{5}{|l|}{ Sibling smokes } \\
\hline No & 2924 & 0.80 & 0.31 & 2.29 \\
\hline Yes & 720 & 0.20 & 0.56 & 2.51 \\
\hline \multicolumn{5}{|l|}{ Friend smoking } \\
\hline None & 1615 & 0.44 & 0.17 & 1.27 \\
\hline Some & 1711 & 0.47 & 0.45 & 2.15 \\
\hline Most & 316 & 0.09 & 0.78 & 4.23 \\
\hline \multicolumn{5}{|l|}{ Ever smoked } \\
\hline No & 2349 & 0.64 & & \\
\hline \multicolumn{5}{|l|}{ Community descriptors } \\
\hline Tobacco outlet density (per 1000 people) & 0.34 & $0.03,1.12$ & 0.03 & -0.07 \\
\hline Distance (mi) to nearest outlet & 0.59 & $0.29,1.19$ & 0.001 & 0.03 \\
\hline Proportion population Black ${ }^{\star}$ & 0.03 & $0.01,0.21$ & -0.03 & -0.19 \\
\hline Proportion population Hispanic* & 0.03 & $0.01,0.09$ & 0.02 & -0.10 \\
\hline Poverty ${ }^{*} \dagger$ & 0.06 & $0.03,0.11$ & 0.02 & -0.12 \\
\hline
\end{tabular}

ever trying smoking. Notably, the coefficient for tobacco outlet density changed little across models and, although small, remained close to statistical significance, in contrast to the other community predictors.

\section{Relation with smoking intensity}

Most of the respondents who had tried smoking (73\%) reported no smoking in the past 30 days. Multivariate model results for smoking intensity among the experimental smokers are reported in table 4. Minority status, friend smoking, age, team sports participation, sensation seeking, tobacco outlet density, proportion population
Black and Hispanic, and poverty, were all associated with smoking intensity at the bivariate level. In the community-only multivariate model, proportion population Black and Hispanic retained a significant inverse relation with smoking intensity. In the full model, friend smoking, age and sensation seeking were all associated with higher intensity and being Black or Hispanic and participating in team sports associated with lower intensity. None of the community characteristics retained a statistically significant association with smoking intensity.

The tobacco outlet density-smoking association was not significantly different for those 18 years and older in 
Table 2 Correlation among the environmental descriptors

\begin{tabular}{|c|c|c|c|c|c|}
\hline \multirow[b]{2}{*}{ Environmental descriptor } & \multicolumn{5}{|c|}{ Correlation } \\
\hline & 1 & 2 & 3 & 4 & 5 \\
\hline $\begin{array}{l}\text { 1. Tobacco outlet density } \\
\text { (per } 1000 \text { people) }\end{array}$ & 1 & & & & \\
\hline $\begin{array}{l}\text { 2. Distance (mi) to nearest } \\
\text { outlet }\end{array}$ & -0.32 & 1 & & & \\
\hline $\begin{array}{l}3 \text { Proportion population } \\
\text { Black }^{*}\end{array}$ & 0.27 & -0.17 & 1 & & \\
\hline $\begin{array}{l}4 \text { Proportion population } \\
\text { Hispanic }^{*}\end{array}$ & 0.26 & -0.13 & -0.10 & 1 & \\
\hline 5 Poverty*,$\uparrow$ & 0.39 & -0.12 & 0.52 & 0.38 & 1 \\
\hline
\end{tabular}

either the tried smoking or the smoking intensity model. Additionally, excluding subjects for whom Zip code centroid was used as a proxy for home address had little impact on the results.

\section{DISCUSSION}

This study highlights the much stronger association between individual health risk factors and youth smoking behaviour compared to community risk factors. Two studies that have examined the relationship between tobacco outlet density or proximity and youth smoking have suggested that tobacco outlet density (but not proximity) is associated with youth smoking. ${ }^{21} 22$ Consistent with those studies, in the unadjusted model we saw a statistically significant association between tobacco outlet density and youth smoking, but not after accounting for additional community and individual risk factors for youth smoking. More importantly, the magnitudes of the community associations with youth smoking were small compared to individual risk factors. Thus, regardless of whether the association of tobacco outlet density reached accepted standards for statistical significance, the small potential effect across a broad range of tobacco outlet densities suggests that policies designed to lower density would have only a small impact on

Table 3 Crude and multivariate association with ever tried smoking

\begin{tabular}{|c|c|c|c|c|c|}
\hline \multirow[b]{2}{*}{ Variable } & \multirow[b]{2}{*}{ Crude OR } & \multicolumn{2}{|c|}{ Community only $+\mathrm{n}=3621$} & \multicolumn{2}{|c|}{ All variables $\neq n=3543$} \\
\hline & & Adjusted OR & $95 \% \mathrm{Cl}$ & Adjusted OR & $95 \% \mathrm{Cl}$ \\
\hline \multicolumn{6}{|l|}{ Individual characteristics } \\
\hline \multicolumn{6}{|l|}{ Categorical } \\
\hline \multicolumn{6}{|l|}{ Gender } \\
\hline Male & Reference & & & & \\
\hline Female & $0.84^{*}$ & & & 1.03 & 0.88 to 1.21 \\
\hline \multicolumn{6}{|l|}{ Race/ethnicity } \\
\hline White & Ref & & & & \\
\hline Black & 0.85 & & & 0.85 & 0.62 to 1.18 \\
\hline Hispanic & $1.24^{*}$ & & & 1.18 & 0.88 to 1.59 \\
\hline Mixed race/other & 1.13 & & & 1.08 & 0.77 to 1.50 \\
\hline \multicolumn{6}{|l|}{ Sibling smokes } \\
\hline No & Ref & & & & \\
\hline Yes & $2.85^{\star}$ & & & $2.13^{*}$ & 1.75 to 2.59 \\
\hline \multicolumn{6}{|l|}{ Friend smoking } \\
\hline None & Ref & & & & \\
\hline Some & $3.93^{*}$ & & & $2.60^{*}$ & 2.19 to 3.10 \\
\hline Most & $17.14^{*}$ & & & $7.01^{*}$ & 5.05 to 9.74 \\
\hline \multicolumn{6}{|l|}{ Continuous } \\
\hline Age (for each additional year) & $1.39^{*}$ & & & $1.23^{*}$ & 1.16 to 1.31 \\
\hline Socioeconomic status & $0.76^{*}$ & & & $0.82^{*}$ & 0.74 to 0.91 \\
\hline Movie smoking exposure & $5.14^{*}$ & & & $2.66^{*}$ & 1.95 to 3.63 \\
\hline Team sports participation & $0.59^{*}$ & & & $0.69^{*}$ & 0.54 to 0.89 \\
\hline Sensation seeking & $20.71^{*}$ & & & $7.72^{*}$ & 5.26 to 11.34 \\
\hline \multicolumn{6}{|l|}{ Community characteristics } \\
\hline Tobacco outlet density (per 1000 people) & $1.30^{*}$ & 1.28 & 0.97 to 1.70 & 1.27 & 0.92 to 1.76 \\
\hline $\begin{array}{l}\text { Tobacco outlet proximity (distance in miles to } \\
\text { nearest outlet) }\end{array}$ & 0.86 & 0.94 & 0.69 to 1.27 & 0.96 & 0.67 to 1.36 \\
\hline Proportion population Black§ & 0.80 & $0.59^{*}$ & 0.42 to 0.83 & 0.93 & 0.53 to 1.61 \\
\hline Proportion population Hispanic§ & 1.47 & 0.87 & 0.49 to 1.55 & 0.88 & 0.41 to 1.87 \\
\hline Poverty§ી & 2.06 & $3.66^{*}$ & 1.07 to 12.42 & 0.74 & 0.17 to 3.22 \\
\hline \multicolumn{6}{|l|}{$\begin{array}{l}{ }^{*} p<0.05 \\
\text { †Pseudo } R^{2}=0.003 \\
\text { †Pseudo } R^{2}=0.20 \text {. } \\
\text { §For each adolescent's census tract. } \\
\text { ПProportion of families with income below the poverty level. }\end{array}$} \\
\hline
\end{tabular}


Table 4 Crude and multivariate association with smoking intensity among experimental smokers

\begin{tabular}{|c|c|c|c|c|c|}
\hline \multirow[b]{2}{*}{ Variable } & \multirow[b]{2}{*}{ Crude OR } & \multicolumn{2}{|c|}{ Community only $+n=1289$} & \multicolumn{2}{|c|}{ All variables $¥ n=1263$} \\
\hline & & Adjusted OR & $95 \% \mathrm{Cl}$ & Adjusted OR & $95 \% \mathrm{Cl}$ \\
\hline \multicolumn{6}{|l|}{ Individual characteristics } \\
\hline \multicolumn{6}{|l|}{ Categorical } \\
\hline \multicolumn{6}{|l|}{ Gender } \\
\hline Male & Reference & & & & \\
\hline Female & 0.93 & & & 1.05 & 0.84 to 1.33 \\
\hline \multicolumn{6}{|l|}{ Race/ethnicity } \\
\hline White & Reference & & & & \\
\hline Black & $0.25^{*}$ & & & $0.48^{*}$ & 0.30 to 0.79 \\
\hline Hispanic & $0.40^{*}$ & & & $0.46^{\star}$ & 0.31 to 0.69 \\
\hline Mixed race/other & $0.60^{*}$ & & & $0.53^{\star}$ & 0.34 to 0.85 \\
\hline \multicolumn{6}{|l|}{ Sibling smokes } \\
\hline No & Reference & & & & \\
\hline Yes & 1.21 & & & 0.98 & 0.76 to 1.26 \\
\hline \multicolumn{6}{|l|}{ Friend smoking } \\
\hline None & Reference & & & & \\
\hline Some & $4.73^{*}$ & & & $3.37^{*}$ & 2.37 to 4.81 \\
\hline Most & $33.62^{\star}$ & & & $20.27^{*}$ & 13.22 to 31.08 \\
\hline \multicolumn{6}{|l|}{ Continuous } \\
\hline Age (for each additional year) & $1.37^{*}$ & & & $1.32^{*}$ & 1.21 to 1.44 \\
\hline Socioeconomic status & 1.10 & & & 1.09 & 0.94 to 1.26 \\
\hline Movie smoking exposure & 1.29 & & & 1.04 & 0.68 to 1.59 \\
\hline Team sports participation & $0.36^{*}$ & & & $0.38^{*}$ & 0.26 to 0.55 \\
\hline Sensation seeking & $12.95^{\star}$ & & & $6.57^{*}$ & 3.71 to 11.64 \\
\hline \multicolumn{6}{|l|}{ Community characteristics } \\
\hline Tobacco outlet density (per 1000 people) & $0.62^{*}$ & 0.98 & 0.64 to 1.50 & 1.11 & 0.70 to 1.79 \\
\hline $\begin{array}{l}\text { Tobacco outlet proximity (distance in miles to } \\
\text { nearest outlet) }\end{array}$ & 1.32 & 0.76 & 0.48 to 1.20 & 0.74 & 0.45 to 1.20 \\
\hline Proportion population Black§ & $0.15^{\star}$ & $0.12^{*}$ & 0.07 to 0.22 & 0.42 & 0.18 to 1.00 \\
\hline Proportion population Hispanic§ & $0.20^{\star}$ & $0.13^{*}$ & 0.06 to 0.32 & 0.43 & 0.14 to 1.33 \\
\hline Poverty§'ף & $0.02^{*}$ & 1.54 & 0.24 to 9.96 & 1.14 & 0.13 to 10.03 \\
\hline $\begin{array}{l}{ }^{*} p<0.05 \\
\dagger \text { Pseudo } R^{2}=0.02 \\
\text { †Pseudo } R^{2}=0.15 \\
\text { §For each adolescent's census tract. } \\
\text { शP Proportion of families with income below the povert }\end{array}$ & & & & & \\
\hline
\end{tabular}

adolescent smoking. In contrast, the associations between team sports participation and both smoking outcomes were large enough to suggest that interventions and policies aiming to support those activities could help prevent adolescent smoking.

This study used Bronfenbrenner's Ecological Systems Theory to frame the possible joint effects of individuallevel, microsystem, mesosystem and exosystem variables on youth smoking. When variables were scaled so as to compare effect sizes, our findings indicated a relative importance of individual-level variables compared to the community variables we studied. We suggest that empirical multilevel studies pay attention to estimating effects that allow for such comparisons, in addition to focusing on statistical significance. Although we found no strong associations with smoking for the community variables studied, this study does not rule out the possibility that other neighbourhood characteristics, such as measures of social capital or neighbourhood smoking, may have an important impact on youth smoking. In fact, one study using the Brofenbrenner model found that neighbourhood rates of youth smoking affected adolescent smoking trajectories, over and above individual risk factors. ${ }^{41}$

The association between some risk factors and smoking was present for trying smoking but not smoking intensity among experimental smokers, underlying the importance of modelling different smoking transitions separately. Trying smoking is strongly influenced by social risk factors (sibling smoking, friend smoking, movie smoking and team sports participation). Among experimental smokers, smoking intensity continues to be associated with smoking by some social influence factors-peers, team sports and exposure to tobacco marketing, ${ }^{35}{ }^{42}$ but is also is predominantly driven by addiction processes. ${ }^{43}$ In this study, sensation seeking was a risk factor for trying smoking and higher smoking intensity, consistent with other research. ${ }^{45}$ Sensation-seeking level probably captures, in part, biological characteristics that promote experience 
seeking ${ }^{46}$ and tolerance of deviance, ${ }^{47}$ but it may also be associated with higher sensitivity to the addictive influence of nicotine. ${ }^{48}$ Given its large association with both smoking outcomes in this study, research on using sensation seeking to target high-risk adolescents, ${ }^{49}$ modifying risk factors that affect sensation seeking deserve greater emphasis. For example, one study suggested that higher exposure to adult-rated movies resulted in higher growth in sensation seeking during adolescence. ${ }^{50}$

Consistent with other studies that have distinguished between trying smoking and smoking intensity, ${ }^{51}$ some characteristics were associated with one outcome but not the other. Exposure to smoking in movies was associated with trying smoking but not smoking intensity, consistent with some other reports. ${ }^{35} 42$ Minority youth tried smoking at rates similar to White youth, but minority ever smokers had much lower smoking intensity than Whites. This finding is not surprising, given that minority adolescents have lower rates of smoking compared with Whites, ${ }^{52} 53$ with larger temporal declines in smoking among Black adolescents ${ }^{54}$ and lower rates of progression to regular use. ${ }^{55}$ Studies of trying smoking have been inconsistent, with some confirming lower rates among minorities, ${ }^{56}$ whereas others, ${ }^{57}$ including this one, did not. Why minority youth that try smoking have lower-smoking intensity than Whites deserves further research, given that the finding holds across studies; ${ }^{52} 55$ minority adolescents could be less susceptible to nicotine addiction in its earliest stages or social or family circumstances could reduce the likelihood of progression of experimental smoking during adolescence.

This study was limited in that it relied on crosssectional data and therefore cannot address temporality. However, it would be unusual to see a weak correlation in a cross-sectional study become a key predictor in a longitudinal one. The national scope of the study could be viewed as a strength but precluded us from directly assessing where tobacco outlets were in each community. Instead, we relied on available commercial data, subject to higher levels of error. Although this limitation could have widened CIs due to random error, we have no reason to believe that the error is larger in some neighbourhoods than others, which would lead to biased estimates. We suggest that, even if the results were statistically significant, the size of the associations were still small for tobacco outlet density and the other community characteristics we measured.

Compared to individual risk factors, tobacco outlet density might be less relevant for minors who are legally constrained in their purchase of tobacco. One previous study of adolescent smoking found no association for tobacco outlet density but a positive association between access-the proportion of stores that illegally sell to minors-and youth smoking. ${ }^{25}$ This suggests that tobacco outlet density could be more important in determining smoking patterns among adults, who are less constrained in their purchase of tobacco at retail outlets. Although we found no evidence for that in the small number of adults present in this sample, further study in adult samples may be indicated. Our study did not explicitly measure exposure to tobacco storefront advertising in the context of community-level influences and therefore cannot address this issue explicitly-we cannot rule out a storefront advertising influence without more elaborate measurements of access to this particular aspect of tobacco retailing. Tobacco outlet density should be a proxy for exposure to storefront advertising but would not capture individual differences in how adolescents respond to or remember it, which could explain differences between our findings and those of others who assessed recollection of storefront advertising. ${ }^{58}$ Finally, we studied tobacco density and proximity at home, not in school. McCarthy et al. looked at the relationship between tobacco retail density near schools and youth tobacco use and found that the effects were limited to trying smoking (not established smoking), and only among high-school students in urban areas. ${ }^{59}$ However, their work did not include the depth of individual-level variables presented in this analysis. Future studies should consider the role of tobacco outlet density and proximity around schools in the context of individual risk factors for adolescent smoking.

This study adds to the growing body of evidence that public health campaigns to prevent and reduce youth smoking should emphasise individual risk factors for smoking, including supporting participation in team sports, minimising exposure to movie smoking, addressing the social influence of friend smoking and addressing experience seeking among high sensation-seekers.

\section{Author affiliations}

${ }^{1}$ Department of Pediatrics, Geisel School of Medicine at Dartmouth, Lebanon, New Hampshire, USA

${ }^{2}$ Dartmouth-Hitchcock Norris Cotton Cancer Center, Lebanon,

New Hampshire, USA

${ }^{3}$ Cancer Control Research Program, Norris Cotton Cancer Center, Lebanon, New Hampshire, USA

${ }^{4}$ The Dartmouth Institute for Health Policy and Clinical Practice, Geisel School of Medicine at Dartmouth, Lebanon, New Hampshire, USA

${ }^{5}$ Community \& Family Medicine, The Geisel School of Medicine at Dartmouth, Hanover, New Hampshire, USA

Contributors All authors (1) made substantial contributions to conception and design, acquisition of data or analysis and interpretation of data;

(2) drafted the article or revised it critically for important intellectual content and (3) approved of the final version to be published.

Funding This work was supported by the National Institutes of Health CA77026 (JD) and 1K23AG036934 (EB).

\section{Competing interests None.}

Ethics approval The study was approved by the Committee for the Protection of Human Subjects at Dartmouth Medical School.

Provenance and peer review Not commissioned; externally peer reviewed.

Data sharing statement Data are available from the authors upon request.

\section{REFERENCES}

1. Sargent JD, Tanski S, Stoolmiller M, et al. Using sensation seeking to target adolescents for substance use interventions. Addiction 2010;105:506-14. 
2. Stephenson MT, Helme DW. Authoritative parenting and sensation seeking as predictors of adolescent cigarette and marajuana use. J Drug Educ 2006;36:247-70.

3. Bauman KE, Foshee VA, Linzer MA, et al. Effect of parental smoking classification on the association between parental and adolescent smoking. Addict Behav 1990;15:413-22.

4. Conrad KM, Flay BR, Hill D. Why children start smoking cigarettes: predictors of onset. Br J Addict 1992;87:1711-24.

5. Fleming $\mathrm{CB}$, Kim H, Harachi TW, et al. Family processes for children in early elementary school as predictors of smoking initiation. $J$ Adolesc Health: Official Publication Soc Adolesc Med 2002;30:184-9.

6. Jackson C, Henriksen L. Do as I say: parent smoking, antismoking socialization, and smoking onset among children. Addict Behav 1997;22:107-14.

7. Biglan A, Duncan TE, Ary DV, et al. Peer and parental influences on adolescent tobacco use. J Behav Med 1995;18:315-30.

8. Flay BR, Hu FB, Siddiqui O, et al. Differential influence of parental smoking and friends' smoking on adolescent initiation and escalation of smoking. J Health Soc Behav 1994;35:248-65.

9. DiFranza JR, Wellman RJ, Sargent JD, et al. Tobacco promotion and the initiation of tobacco use: assessing the evidence for causality. Pediatrics 2006;117:e1237-48.

10. National Cancer Institute. The role of the media in promoting and reducing tobacco use. Tobacco Control Monograph No. 19. Bethesda, MD: US Department of Health and Human Services, National Institutes of Health, National Cancer Institute. NIH Pub. No. 07-6242, 2008 June.

11. US Department of Health and Human Services. Preventing tobacco use among youth and young adults: a report of the surgeon general. Atlanta, GA: US Department of Health and Human Services, Centers for Disease Control and Prevention, National Center for Chronic Disease Prevention and Health Promotion, Office on Smoking and Health, 2012.

12. Adachi-Mejia AM, Primack BA, Beach ML, et al. Influence of movie smoking exposure and team sports participation on established smoking. Arch Pediatr Adolesc Med 2009;163:638-43.

13. Brown KS, Cameron R, Madill C, et al. Outcome evaluation of a high school smoking reduction intervention based on extracurricular activities. Prev Med 2002;35:506-10.

14. Shilts $L$. The relationship of early adolescent substance use to extracurricular activities, peer influence, and personal attitudes. Adolescence 1991;26:613-17.

15. Terry-McElrath YM, O'Malley PM. Substance use and exercise participation among young adults: parallel trajectories in a national cohort-sequential study. Addiction 2011;106:1855-65; discussion 66-7.

16. Terry-McElrath YM, O'Malley PM, Johnston LD. Exercise and substance use among American youth, 1991-2009. Am J Prev Med 2011;40:530-40.

17. Perry CL. Results of prevention programs with adolescents. Drug Alcohol Depend 1987;20:13-19.

18. Master Settlement Agreement. http://www.naag.org/issues/tobacco/ index.php?sdpid=919. $1998 \mathrm{http}: / / \mathrm{www}$. naag.org/issues/tobacco/ index.php?sdpid=919 (accessed 16 Jun 2005)

19. Feighery EC, Henriksen L, Wang Y, et al. An evaluation of four measures of adolescents' exposure to cigarette marketing in stores. Nicotine Tob Res 2006:8:751-9.

20. Henriksen L, Feighery EC, Schleicher NC, et al. Receptivity to alcohol marketing predicts initiation of alcohol use. $J$ Adolesc Health: Official Publication Soc Adolesc Med 2008;42:28-35.

21. Novak SP, Reardon SF, Raudenbush SW, et al. Retail tobacco outlet density and youth cigarette smoking: a propensity-modeling approach. Am J Public Health 2006;96:670-6.

22. Henriksen L, Feighery EC, Schleicher NC, et al. Is adolescent smoking related to the density and proximity of tobacco outlets and retail cigarette advertising near schools? Prev Med 2008;47:210-14.

23. Ogneva-Himmelberger $Y$, Ross L, Burdick W, et al. Using geographic information systems to compare the density of stores selling tobacco and alcohol: youth making an argument for increased regulation of the tobacco permitting process in Worcester, Massachusetts, USA. Tob Control 2010;19:475-80.

24. West JH, Blumberg EJ, Kelley NJ, et al. Does proximity to retailers influence alcohol and tobacco use among Latino adolescents? $J$ Immigr Minor Health 2010;12:626-33.

25. Pokorny SB, Jason LA, Schoeny ME. The relation of retail tobacco availability to initiation and continued smoking. J Clin Child Adolesc Psychol 2003;32:193-204.

26. Peterson NA, Lowe JB, Reid RJ. Tobacco outlet density, cigarette smoking prevalence, and demographics at the county level of analysis. Subst Use Misuse 2005;40:1627-35.
27. Schneider JE, Reid RJ, Peterson NA, et al. Tobacco outlet density and demographics at the tract level of analysis in lowa: implications for environmentally based prevention initiatives. Prev $\mathrm{Sci}$ 2005:6:319-25.

28. Yu D, Peterson NA, Sheffer MA, et al. Tobacco outlet density and demographics: analysing the relationships with a spatial regression approach. Public Health 2010;124:412-16.

29. Hyland A, Travers MJ, Cummings KM, et al. Tobacco outlet density and demographics in Erie County, New York. Am J Public Health 2003;93:1075-6.

30. Cohen JE, Anglin L. Outlet density: a new frontier for tobacco control. Addiction 2009;104:2-3.

31. Bronfenbrenner U. Toward an experimental ecology of human development. Am Psychol 1977;32:513-31.

32. Bronfenbrenner U. The ecology of developmental processes. In: Damon W, Lerner RM, eds. Handbook of child psychology. 5th edn. New York: John Wiley \& Sons, Inc.; 1998:993-1028.

33. Bronfenbrenner U. Developmental research, public policy, and the ecology of childhood. Child Dev 1974;45:1-5.

34. Sargent J, Beach M, Adachi-Mejia A, et al. Exposure to movie smoking: its relation to smoking initiation among US adolescents. Pediatrics 2005;116:1183-91.

35. Sargent JD, Hanewinkel R. Comparing the effects of entertainment media and tobacco marketing on youth smoking in Germany. Addiction 2009:104:815-23.

36. Sargent JD, Worth KA, Beach M, et al. Population-based assessment of exposure to risk behaviors in motion pictures. Commun Methods Meas 2008;2:134-51.

37. Carlos HA, Shi X, Sargent J, et al. Density estimation and adaptive bandwidths: a primer for public health practitioners. Int $J$ Health Geogr 2010;9:39.

38. Shi X. Selection of bandwith type and adjustment side in kernel density estimation over inhomogenous backgrounds. Int J Geogr Inform Sci 2010;24:643-60.

39. Oak Ridge National Laboratory. LandScan global population database. Oak Ridge, TN (4/2/11); http://www.ornl.gov/landscan/ (2 Apr 2011).

40. Esri. Esri StreetMap Premium-advanced geocoding, routing, and cartography. Redlands, CA. http://www.esri.com/data/streetmap/ index.html (2 Apr 2011).

41. Ennett ST, Foshee VA, Bauman KE, et al. A social contextual analysis of youth cigarette smoking development. Nicotine Tob Res 2010;12:950-62.

42. Sargent JD, Gibson J, Heatherton TF. Comparing the effects of entertainment media and tobacco marketing on youth smoking. Tob Control 2009;18:47-53.

43. DiFranza JR, Rigotti NA, McNeill AD, et al. Initial symptoms of nicotine dependence in adolescents. Tob Control 2000;9:313-19.

44. DiFranza JR, Savageau JA, Fletcher K, et al. Measuring the loss of autonomy over nicotine use in adolescents: the DANDY (Development and Assessment of Nicotine Dependence in Youths) study. Arch Pediatr Adolesc Med 2002;156:397-403.

45. Skara S, Sussman S, Dent CW. Predicting regular cigarette use among continuation high school students. Am J Health Behav 2001:25:147-56.

46. Zuckerman M. Behavioral expressions and biosocial bases of sensation seeking. New York: Cambridge University Press, 1994.

47. Newcomb MD, McGee L. Influence of sensation seeking on general deviance and specific problem behaviors from adolescence to young adulthood. J Pers Soc Psychol 1991;61:614-28.

48. Perkins KA, Gerlach D, Broge M, et al. Greater sensitivity to subjective effects of nicotine in nonsmokers high in sensation seeking. Exp Clin Psychopharmacol 2000;8:462-71.

49. Conrod PJ, Castellanos N, Mackie C. Personality-targeted interventions delay the growth of adolescent drinking and binge drinking. J Child Psychol Psychiatry 2008;49:181-90.

50. Stoolmiller M, Gerrard M, Sargent JD, et al. R-rated movie viewing, growth in sensation seeking and alcoho initiation: reciprocal and moderation effects. Prev Sci 2010; 11:1-13.

51. Robinson LA, Murray DM, Alfano CM, et al. Ethnic differences in predictors of adolescent smoking onset and escalation: a longitudinal study from 7 th to 12 th grade. Nicotine Tob Res 2006;8:297-307.

52. Bachman JG, Wallace JM Jr, O'Malley PM, et al. Racial/ethnic differences in smoking, drinking, and illicit drug use among American high school seniors, 1976-1989. Am J Public Health 1991;81:372-7.

53. Lewis PC, Harrell JS, Bradley C, et al. Cigarette use in adolescents: the cardiovascular health in children and youth study. Res Nurs Health 2001;24:27-37. 
54. Nelson MC, Gordon-Larsen P. Physical activity and sedentary behavior patterns are associated with selected adolescent health risk behaviors. Pediatrics 2006;117:1281-90.

55. Flint AJ, Yamada EG, Novotny TE. Black-white differences in cigarette smoking uptake: progression from adolescent experimentation to regular use. Prev Med 1998;27:358-64.

56. Headen SW, Bauman KE, Deane GD, et al. Are the correlates of cigarette smoking initiation different for black and white adolescents? Am J Public Health 1991;81:854-8.
57. Jackson C, Brown JD, L'Engle KL. R-rated movies, bedroom televisions, and initiation of smoking by white and black adolescents. Arch Pediatr Adolesc Med 2007:161:260-8.

58. Henriksen L, Feighery EC, Wang Y, et al. Association of retail tobacco marketing with adolescent smoking. Am J Public Health 2004:94:2081-3.

59. McCarthy WJ, Mistry R, Lu Y, et al. Density of tobacco retailers near schools: effects on tobacco use among students. Am J Public Health 2009;99:2006-13. 